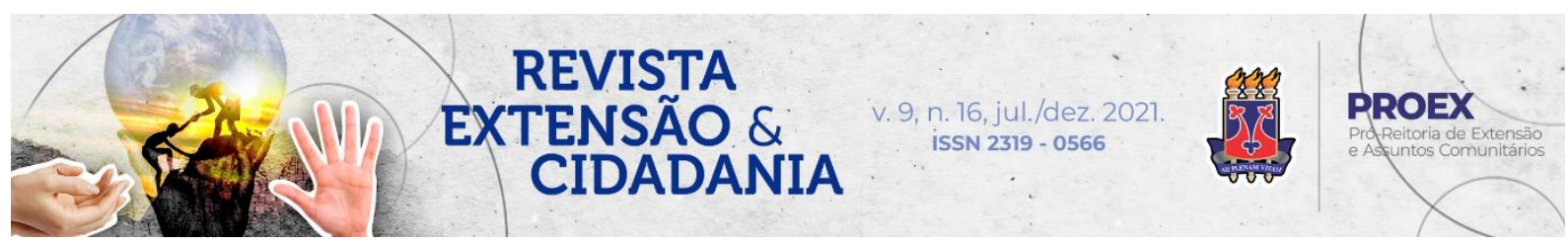

DOI: $10.22481 /$ recuesb.v9i16.8682

\title{
FISICÁ \& ACOLÁ: DISCORRENDO SOBRE A PALAVRA DA CIÊNCIA
}

\section{FISICÁ \& ACOLÁ: DISCOURSING THE WORD OF SCIENCE}

FISICÁ \& ACOLÁ: DISERTANDO SOBRE LA PALABRA DE LA CIENCIA

Danilo Ribeiro de Sá Teles ${ }^{1}$

\begin{abstract}
Resumo: Este documento relata os caminhos, resultados e conclusões de um trabalho desenvolvido em uma escola municipal da cidade de Dourados-MS, decorrente de um projeto de extensão que envolveu estudantes do ensino básico, fundamental e médio, na discussão de temáticas relacionadas a alguns fenômenos físicos e sociais. Lançando mão de uma pesquisa exploratória, com análises das observações realizadas durante a sua execução, o projeto foi desenvolvido por meio de encontros semanais, planejados e executados mediante oficinas pedagógicas, na tentativa de articular teoria e prática, à guisa de alicerçar o protagonismo dos educandos. Fundamentado na apresentação de material ilustrativo lúdico, experimentos de Física e leituras de artigos científicos, foi possível estimular o livre pensar, refletir sobre a desigualdade de gênero na Física e fomentar discussões com jovens estudantes, complementando a sua alfabetização científica e contribuindo para a desmistificação das atividades relativas à Física. Acredita-se que a relevância deste relato é a de contribuir, minimamente que seja, para o aperfeiçoamento da educação de ciências de uma pequena cidade do interior do Brasil, sendo um vetor de divulgação científica e de estímulo ao engajamento de crianças e adolescentes na ciência.
\end{abstract}

Palavras-chave: Educação Científica. Cidadania. Ensino de Física. Feminização.

Abstract: This document reports the paths, results and conclusions of a work developed in a municipal school in the city of Dourados-MS, resulting from an extension project that involved students of basic, elementary and high school, in the discussion of themes related to some physical phenomena and social. The project was developed through weekly meetings, planned and executed from pedagogical workshops, in an attempt to articulate theory and practice, by way of supporting the protagonism of the students. From the presentation of playful illustrative material, physics experiments and reading of scientific articles, it was possible to stimulate free thinking, reflect on gender inequality in physics and encourage discussions with young students, complementing their scientific literacy and contributing to the demystification of activities related to physics. From the presentation of playful illustrative material, physics

\footnotetext{
${ }^{1}$ Doutor em Geofísica Aplicada, pela Universidade Federal da Bahia (UFBA). Professor EBTT de Física, do Instituto Federal de Mato Grosso do Sul (IFMS), Dourados, Mato Grosso do Sul, Brasil. Orcid: https://orcid.org/0000-0001-9725-2762 E-mail: danilo.teles@ifms.edu.br.
} 
experiments and reading of scientific articles, it was possible to stimulate free thinking and encourage discussions with young students, complementing their scientific literacy and contributing to the demystification of activities related to physics. It is believed that the relevance of this report is to contribute to the improvement of science education in a small city in the interior of Brazil, being a vector for scientific dissemination and stimulating the engagement of children and adolescents in science.

Keywords: Scientific Education. Citizenship. Physics teaching. Feminization

Resumen: En este trabajo se describe los caminos, resultados y conclusiones de un trabajo desarrollado en una escuela pública la ciudad de Dourados, Mato Grosso del Sul, resultado de un proyecto de extensión que involucró a estudiantes de la escuela primaria y secundaria, en la discusión de temas relacionados con algunos fenómenos físicos y sociales. El proyecto se desarrolló a través de reuniones semanales, planificadas y ejecutadas a partir de talleres pedagógicos, en un intento de articular teoría y práctica, a modo de apoyar el protagonismo de los estudiantes. A partir de la presentación ilustrativa de material lúdico, experimentos de física y lectura de artículos científicos, fue posible promover el libre pensamiento, reflexionar sobre la desigualdad de género en la física y fomentar las discusiones con jóvenes estudiantes, complementando su alfabetización científica y contribuyendo a la desmitificación de las actividades relacionadas con física. A partir de la presentación de material ilustrativo lúdico, experimentos de física y lectura de artículos científicos, fue posible estimular el libre pensamiento y la discusión con los jóvenes estudiantes, complementando su alfabetización científica y contribuyendo a la desmitificación de las actividades relacionadas con la física. Se cree que la relevancia de este informe es contribuir al mejoramiento de la educación científica en una pequeña ciudad del interior de Brasil, siendo un vector de divulgación científica y estimulando la participación de niños y adolescentes en la ciencia.

Palabras clave: Educación científica. Ciudadanía. Enseñanza de la física. Feminización

\section{Introdução}

As atividades de pesquisa e extensão são compromissos assumidos pelos Institutos Federais de Educação, Ciência e Tecnologia, e realizadas a partir da interlocução com as comunidades acadêmica e local, "[...] com ênfase na produção, desenvolvimento e propagação de conhecimentos científicos e tecnológicos" (BRASIL, 2008, p. 4). Quando bem executadas, exercitam competentemente a tríade ensino, pesquisa e extensão que, juntamente com uma gestão eficiente, a equilibra, tornando-a uma eficaz ferramenta de difusão da ciência, permitindo um processo dialógico com a sociedade (OLIVEIRA; COSTA, 2018).

Posta em prática, torna-se, então, instrumento na direção de uma educação pública e democrática, corroborando com uma ruptura do dualismo estrutural e que, efetivamente,

Revista Extensão \& Cidadania, v. 9, n. 16, p. 166-177, jul./dez. 2021. 
construa uma autonomia, privilegiando uma formação omnilateral, ou seja, uma educação para a plena cidadania (ARRUDA; ZANOTELLO, 2020).

Sendo coerente a uma das seções deste artigo, que trata da feminização da ciência, resisto à linguagem neutra, optando por escrever no feminino. Por conseguinte, considerando dados da Pnad, Pesquisa Nacional por Amostra de Domicílios Contínua (IBGE, 2019), que revela ser superior o número de mulheres em relação aos homens no Brasil, escrevo para a maioria da população brasileira, sem querer abrir mão, contudo, dos eventuais leitores que possam prestigiar o texto com sua leitura, "[...] exatamente porque o lugar dos homens está tão bem assegurado na pesquisa acadêmica é que arrisquei a transgressão de escrever (...) no feminino universal" (DINIZ, 2012, p. 9).

A contemporaneidade mergulha a cidadã em uma complexa e constante rede de entendimentos (e desentendimentos), tornando necessária a compreensão dos diferentes códigos e linguagens relacionados às novas e antigas tecnologias para a completa inclusão. $\mathrm{Na}$ concepção de Oliveira e Costa (2020, p. 243): “[...] à escola compete a formação para atender às demandas do capitalismo, ao mesmo tempo que deve potencializar a educanda para lidar, compreender e contribuir com a resolução dos problemas sociais."

Hoje, ser alfabetizada científica e tecnicamente é uma necessidade da cidadã que, curiosa pela invasão do mundo externo na escola, vive rodeada por equipamentos eletrônicos cujos princípios de funcionamento se relacionam com conhecimentos físicos, dotando a estudante de condições para compreender, não só a ciência e a tecnologia por trás de um produto ou de um empreendimento, mas também, todos os seus desdobramentos sociais e seus impactos econômicos (PIETROCOLA, 2001; CHASSOT, 2003).

Por outro lado, é muito pequena a quantidade de pessoas capazes de empregar os conhecimentos escolares em suas vivências diárias e no planejamento do futuro, não conseguindo aplicar, razoavelmente, o que viu, mas não aprendeu (nem apreendeu) na escola, em situações cotidianas. Constata-se, portanto, urgente e imprescindível, reconsiderar o ensino de ciências no Brasil, estabelecendo-o como prioridade nas escolas desde o ensino fundamental. Da mesma forma, é premente o envolvimento de meninas e mulheres nessa discussão, tornando o ambiente menos hostil e preconceituoso para elas, contribuindo para o seu entendimento, controle e previsões das transformações que ocorrem na natureza, auxiliando na construção do seu empoderamento na leitura do universo (CHASSOT, 2003; MELO; RODRIGUES, 2018).

Revista Extensão \& Cidadania, v. 9, n. 16, p. 166-177, jul./dez. 2021. 
Nessa perspectiva, o relato ora apresentado traz a experiência vivenciada com um grupo de estudantes da Educação Básica de Dourados, Mato Grosso do Sul, fundado na realização, em 2018, do projeto de extensão intitulado Fazendo Ciência. Seu desenvolvimento teve como pretensão complementar a formação básica de cidadã, colaborando para o aditamento da capacidade de aprender, e elevar a compreensão do ambiente natural e social, estimulando o interesse das jovens estudantes sul-mato-grossenses pela ciência, incentivando o raciocínio lógico e investigativo a respeito de teorias e hipóteses que expliquem determinados fenômenos físicos, auxiliando na empregabilidade dos conhecimentos construídos na escola, no seu dia-adia e no planejamento futuro.

\section{Curiosidade, método e ação}

Como uma obra referenciada em outras, esta se inspira nas reflexões sobre cidadania conduzidas por Milton Santos, Paulo Freire, entre outros intelectuais brasileiros. Parafraseando o primeiro, tenta delimitar "a diferença entre a retórica e o fato. O respeito ao indivíduo é a consagração da cidadania, pela qual uma lista de princípios gerais e abstratos se impõe como um corpo de direitos concretos individualizados" (SANTOS, 2012, p. 19).

Foram realizados experimentos e discutidos textos técnico-científicos, com diferentes graus de complexidade, que contribuíram para despertar o fascínio das estudantes pelos fenômenos naturais, estimulá-las a se interessar e entender as tecnologias que já fazem parte do seu cotidiano, e despertar o gosto por ciências.

De forma ativa e reflexiva, com o intuito de possibilitar a apropriação e construção de conhecimentos, os encontros foram planejados e realizados como oficinas pedagógicas, articulando teoria e prática, procurando edificar o protagonismo das educandas envolvidas. Para proporcionar a compreensão e análise dos acontecimentos observados, este relato de experiência foi construído alicerçado em uma pesquisa exploratória com análises das observações realizadas durante a execução do projeto, procurando compreendê-la e averiguar sua inter-relação com outros fatos (PAVIANI; FONTANTA, 2009).

As repercussões do projeto foram discutidas em dois tópicos, a saber, "Física, palavra feminina" e "Cientista, eu?". Enquanto este reflete sobre as atividades desenvolvidas com adolescentes, estudantes do ensino fundamental, que ainda não tiveram um contato mais formal com a Física, aquele aborda o desenvolvimento de uma atividade extensionista com meninas,

Revista Extensão \& Cidadania, v. 9, n. 16, p. 166-177, jul./dez. 2021. 
por meio das ações e reflexões das três bolsistas que participaram do projeto, e do estímulo que deram à integração das estudantes do Instituto Federal de Mato Grosso do Sul (IFMS), em atividades científicas. Em acordo com Bolzani:

\begin{abstract}
Ações que ampliam a participação feminina na atividade científica devem gerar ganhos substantivos nos próximos anos. Mas os números totalizados não revelam a desigualdade da proporção entre os gêneros quando se olha para as áreas de conhecimento separadamente. Áreas tradicionalmente tidas como masculinas continuam com perfil de distribuição fortemente desigual. Por exemplo, em ciências agrícolas essa proporção é de $74 \%$ de homens e $36 \%$ de mulheres; em ciências exatas e da terra, que engloba física, química e matemática, a participação feminina é de $32 \%$ e nas engenharias, $39 \%$.
\end{abstract} (BOLZANI, 2017, p. 58)

A pretensão do proponente em compor uma equipe predominantemente feminina vai ao encontro de uma tentativa de desconstruir, já entre estudantes do ensino fundamental, a ideia da inaptidão das mulheres para Física e outras ditas searas masculinas.

A partir das oficinas, habilitam-se as jovens pesquisadoras a reconhecer o problema em seu dia-a-dia, investigá-lo e modificá-lo, possibilitando "vivenciar situações concretas e significativas, baseada no tripé: sentir-pensar-agir, com objetivos pedagógicos" (PAVIANI; FONTANTA, 2009, p. 78).

Com as oficinas, estimula-se o trabalho em equipe, fomentando a emancipação da estudante como protagonista no processo de aprendizagem e construção de conhecimentos que “[...] precisam ser questionados, avaliados e modificados sob a luz dos estudos de gênero, ciência e tecnologia, para que as mulheres tenham uma participação efetiva em condições de igualdade com os homens" (YANNOULAS, 2013, p. 103).

Espaços como os laboratórios científicos são de fundamental importância para descortinar um fenômeno físico e desprendê-lo. Disponibilizar às estudantes do ensino básico o contato com experimentos e demonstrações de Física poderá estimular nesse público o pensamento científico, e possibilita o entendimento do que acontece e o que provoca os fenômenos físicos naturais.

\title{
Física, palavra feminina
}

O título dessa seção, "Física, palavra feminina", surgiu logo nos primeiros encontros, na fase de elaboração das atividades com as bolsistas. Ao idealizar uma das primeiras atividades

Revista Extensão \& Cidadania, v. 9, n. 16, p. 166-177, jul./dez. 2021. 
às estudantes, as bolsistas compuseram uma palavra-cruzada, abordando alguns fenômenos e conceitos científicos. Para completar uma proposição com seis letras, a referência sugerida foi "palavra feminina que trata de fenômenos como movimento, temperatura e calor".

Considerando a complexidade dos fatores que tradicionalmente impedem as mulheres de exercerem atividades científicas, como os preconceitos sociais que reproduzidos, conscientemente ou não, acabam afastando as meninas de algumas áreas, optou-se por uma maioria de garotas na composição da equipe do projeto.

Como a proposta foi contemplada com apoio financeiro, garantindo o pagamento de bolsas para estudantes do ensino médio, o projeto contou com três alunas que auxiliaram na execução das oficinas, e facilitaram uma maior inclusão das meninas. Na seleção das bolsistas, deu-se preferência às jovens discentes do ensino médio, primando muito mais pelo entusiasmo das adolescentes em participar da atividade, que por seus respectivos históricos escolares.

No ensino médio, este projeto teve como objetivo tratar de temas científicos e sociais com estudantes do sexo feminino, de forma a atuar no constrangedor quadro sul-americano de escassa participação das meninas e mulheres na ciência. Com a participação das bolsistas, foi possível obter mais sucesso na interação com as discentes, tanto do ensino fundamental quanto do médio, desestruturando preconceitos sobre a inacessibilidade da Física.

Pretensiosamente, fez-se questão de evidenciar a participação de meninas em um projeto de Física, apresentando, com propriedade, conceitos científicos, além de propor discussões com as estudantes do ensino básico sobre as diferenças nas trajetórias de homens e mulheres na ciência, potencializando o seu engajamento, mais do que, simplesmente, incluir mais mulheres nos espaços ocupados pelos homens (YANNOULAS, 2013).

Márcia Barbosa e Betina Lima (2013) discutindo sobre as mulheres na Física do Brasil, apontam a institucionalização da ciência com processo de exclusão do feminino, não resultando as disparidades de gênero de diferenças inatas a ambos os sexos. Segundo as autoras:

[...] assim, a própria concepção de ciência é elaborada conforme a lógica binária, oposta e assimétrica de gênero, ou seja, os valores considerados para ciência estão alocados no polo masculino (razão, objetividade, competitividade...) do qual o feminino é construído como oposto. (BARBOSA; LIMA, 2013, p. 73)

Iniciaram-se os trabalhos com a apresentação de mulheres cientistas brasileiras e estrangeiras e a leitura e debate de textos sobre a reduzida presença das meninas em projetos de

Revista Extensão \& Cidadania, v. 9, n. 16, p. 166-177, jul./dez. 2021. 
pesquisa e feiras de ciências sul-mato-grossenses. Esta discussão foi continuada por três encontros que contaram com a curadoria das jovens pesquisadoras do IFMS.

\section{Cientista, eu?}

O subtítulo acima foi inspirado no questionamento incrédulo de muitos jovens estudantes frente às "inalcançáveis" ciências exatas. Sobretudo frente à Física, é comum notar o autoboicote diante de tão famigerada disciplina. A propósito, o ensino exige a reflexão crítica sobre a prática, sendo "[...] a tarefa coerente do educador que pensa certo é, exercendo como ser humano a irrecusável prática de inteligir, desafiar o educando com quem se comunica, produzir sua compreensão do que vem sendo comunicado" (FREIRE, 2004, p. 38).

Diante disso, o projeto de extensão intitulado Fazendo Ciência, fonte deste relato de experiência, desprovido do propósito de ministrar a disciplina de Física, teve como pretensão desmistificar esta ciência entre jovens estudantes, possibilitando uma maior aceitação e interação em estudos futuros.

As atividades foram desenvolvidas em uma escola da região, vizinha à instituição proponente, atendendo discentes do $8^{\circ}$ e $9^{\circ}$ anos do ensino fundamental, e contando com a participação de jovens cursistas do ensino médio integrado.

Foram executadas oficinas de Física, com a construção de experimentos feitos de materiais reciclados e com objetos de baixo custo, possibilitando a elaboração de artefatos com diferentes níveis de complexidade. Kits experimentais profissionais também foram utilizados. As reuniões ocorreram na escola e no campus Dourados, do IFMS.

Inicialmente, lançou-se mão da apresentação de histórias em quadrinhos e séries televisivas com o intuito de entusiasmar as educandas, contextualizando a ciência de forma lúdica. As reflexões orbitaram em torno das tirinhas obtidas do Material do Estudante do Gref, acrônimo de Grupo de Reelaboração do Ensino de Física, e de alguns episódios do vídeo educacional "De Onde Vem", da TV Escola - nessa série, a protagonista "Kika", menina esperta e curiosa, questiona a origem das coisas. São vinte episódios curtos que explicam sobre o arco-íris, dia e a noite, o vidro, a eletricidade, etc.

Os mediadores proporcionaram um momento de discussão coletiva, fomentando uma chuva de ideias sobre o conceito de Física das estudantes: o que já ouviram falar sobre esta área

Revista Extensão \& Cidadania, v. 9, n. 16, p. 166-177, jul./dez. 2021. 
do conhecimento, os fenômenos envolvidos com o dia e a noite, as estações do ano, o arco-íris, os objetos elétricos, a música e os fenômenos atmosféricos.

Embora o projeto tenha enfatizado a ação, primou também pela reflexão, não abrindo mão da base teórica. Sendo assim, após a discussão, as alunas foram conduzidas à biblioteca da escola para uma consulta ao dicionário, em busca de conceitos formais sobre Física. Fez-se questão de levá-las à biblioteca e não em trazer os dicionários à sala, com a intenção de agregar este importante espaço também para o estudo da ciência, e estimular o protagonismo das discentes na coleta de informações, dando-lhes condições para a construção do conhecimento.

Após a tempestade lúdico-científica proporcionada pelas jovens pesquisadoras, elas foram convidadas a conhecer os laboratórios do campus do IFMS. Contando com cursos nas áreas de Ciências Exatas, os laboratórios do Instituto possuem equipamentos que permitem contextualizar a Física com outras atividades e fenômenos, possibilitando uma interessante interlocução com/entre as estudantes.

No laboratório, foi viabilizada a interação das estudantes com experimentos que reproduziam grandezas Físicas e alguns fenômenos térmicos, acústicos e elétricos. Entre eles, destaca-se a oficina de medidas Físicas, onde se apresentou objetos, representando as grandezas mais corriqueiras, como massa, comprimento, área e volume. As oficinas consistiram em provocar as estudantes a associar os objetos às suas respectivas unidades de medida, correspondendo, por exemplo, objetos de diferentes comprimentos ao metro, e volumes diversos à unidade de metro cúbico. Para a obtenção da unidade de massa, utilizaram-se garrafas pet e bolinhas de gude; as esferas eram adicionadas, ou retiradas, à/da garrafa, até a estudante obter 1,0 kg, mensurado com uma balança ordinária.

As atividades elencadas, exibidas antes de uma apresentação protocolar da disciplina de Física, dispensando algumas de suas formalidades, cálculos e leis, foram muito salutar. Não que se tenha aberto mão da lisura científica, mas, potencializar o fenômeno em detrimento à burocracia científica contribuiu para um maior entusiasmo das jovens discentes. Citando Vianna:

[...] podemos encontrar profundas inquietações na área de Alfabetização e Letramento científicos e tecnológicos. Sabemos que nem todos os estudantes da educação básica seguirão estudos na área científica. Mas é preciso fazê-los entender o mundo que os rodeia. [...] independentemente da profissão que vão seguir, todos atuarão na sociedade em que vivem, como cidadãos. (VIANNA, 2009, p.136)

Revista Extensão \& Cidadania, v. 9, n. 16, p. 166-177, jul./dez. 2021. 
Acredita-se que o desenvolvimento de novas estratégias de ensino de Física, baseadas em experimentos e novas tecnologias, podem contribuir para despertar o interesse de crianças e adolescentes. Trata-se de construir uma visão da Física que esteja voltada para a formação de uma cidadã contemporânea, atuante e solidária, com instrumentos para compreender, intervir e participar ativamente na sua realidade (BRASIL, 2002).

\section{Resultados e discussão}

Refletindo sobre a interação das estudantes durante o desenvolvimento deste Projeto, é possível afirmar que as oficinas auxiliaram no entendimento dos fenômenos físicos a partir de recursos lúdicos que estimularam a curiosidade, a criatividade e habilidade das estudantes do ensino fundamental e médio, despertando o interesse pelo campo científico.

Um evento que merece destaque foi a oficina de medidas padrão, apesar da maioria das estudantes demonstrarem familiaridade com algumas grandezas Físicas fundamentais, como massa, comprimento e tempo, suas respectivas unidades no sistema internacional - quilograma, metro e segundo - e as grandezas derivadas, cujas unidades são metro quadrado e metro cúbico, apenas uma minoria conseguia associar essas unidades à sua medida correspondente.

Atento ao alerta de Paulo Freire, de que "[...] transformar a experiência educativa em puro treinamento técnico é amesquinhar o que há de fundamentalmente humano no exercício educativo: o seu caráter formador" (FREIRE, 2004, p. 33), procurou-se desenvolver as atividades vinculadas à experiência cotidiana dos alunos, de forma a instrumentalizá-los de uma melhor compreensão e atuação na realidade.

Um exemplo curioso foi obtido no estudo da unidade área: questionadas sobre a unidade correspondente a esta grandeza, a maioria das alunas apontou o metro-quadrado $\left(\mathrm{m}^{2}\right)$. Entretanto, diante de diversos objetos de diferentes áreas, menos da metade conseguiu corresponder uma unidade de área, $1 \mathrm{~m}^{2}$, com um objeto com esta medida. Diante desta dificuldade, fez-se uma oficina extra, erigindo essa percepção pela construção dos próprios experimentos, aproximando o saber escolar do saber cotidiano.

Retratando a realidade que apresenta uma iniquidade de gênero em relação ao número de pesquisadoras comparado ao número de homens na mesma posição, e associando com a realidade brasileira, articulou-se com as estudantes quais as soluções poderiam ser tomadas para garantir, pelo menos localmente, uma equidade de gênero. Apesar da timidez verificada nas

Revista Extensão \& Cidadania, v. 9, n. 16, p. 166-177, jul./dez. 2021. 
primeiras reuniões, boas ideias surgiram no decorrer do projeto, a exemplo da proposição de eventos e editais de iniciação científica que garantissem uma participação mais destacada das meninas.

\section{Considerações finais}

Desconstruindo os preconceitos edificados ao longo da vida escolar, e, muitas vezes, ratificados pela família, o projeto auxiliou dezenas de estudantes a compreender mais adequadamente alguns fenômenos físicos, complementar o seu letramento científico e, esperase, aumentará o sucesso desses estudantes frente à disciplina de Física nos ensinos médio e superior.

Com as meninas do ensino médio, futuras, pesquisadoras ou ocupantes de qualquer profissão de sua livre escolha, foi benfazeja a discussão da equidade de gênero a partir da ótica de um problema brasileiro, com reflexos expressivos no Mato Grosso do Sul. E ainda mais interessante foi apresentar diagnósticos e soluções para maior inclusão feminina na ciência douradense.

Apesar de estar ciente de que problemas complexos exigem soluções complexas, e que uma assimetria dessa magnitude não desaparecerá da noite para o dia, acredita-se que uma fagulha foi acesa, com grande potencial de aquecer e iluminar mentes e corações de jovens pesquisadoras e pesquisadores.

O projeto foi ao encontro, e logrou êxito, de complementar a formação básica cidadã, que é objetivo do ensino fundamental, colaborando para o desenvolvimento da capacidade de aprender e melhorar a compreensão do ambiente natural, social e cultural. De encontro ao androcentrismo, seu mérito foi o de rechaçar a naturalidade com que temos, como sociedade, encarado situações indecentes, como a desigualdade entre mulheres e homens nos cargos de chefia, nas carreiras científicas, e o analfabetismo científico das nossas cidadãs. Trata-se, nesse caso, de um pequeno gesto docente que se espera reverberar nas jovens estudantes sul-matogrossenses.

Revista Extensão \& Cidadania, v. 9, n. 16, p. 166-177, jul./dez. 2021. 


\section{Agradecimentos}

O autor agradece ao IFMS pelo aporte financeiro para auxílio do projeto e pagamento de bolsas de extensão às estudantes, assim como os servidores das escolas municipais Cyríaco Félix de Toledo e Clarice Bastos Rosa.

\section{Referências}

ARRUDA, Fábio Pinto de; ZANOTELLO, Marcelo. Educação Profissional e Tecnológica. Revista Labor, v. 2, n. 24, p. 24-45, jul./dez. 2020.

BARBOSA, Marcia C.; LIMA, Betina S. Mulheres na Física do Brasil: Por que tão poucas? E por que tão devagar? In: YANNOULAS, Silvia Cristina (Coord.). Trabalhadoras: análise da feminização das profissões e ocupações. Brasília: Editorial Abaré, 2013.

BOLZANI, Vanderlan da Silva. Mulheres na Ciência: por que ainda somos tão poucas? Ciência e Cultura, v. 69, n. 4, p. 56-59, out./dez. 2017.

BRASIL. Lei $\mathbf{n}^{\mathbf{0}}$ 11.892, de 29 de dezembro de 2008. Institui a Rede Federal de Educação Profissional, Científica e Tecnológica, cria os Institutos Federais de Educação, Ciência e Tecnologia. Disponível em: http: http://www.planalto.gov.br/ccivil_03/_ato20072010/2008/lei/111892.htm. Acesso em: 2 dez. 2020.

BRASIL. Secretaria de Educação Média e Tecnológica (Semtec/MEC). PCN + Ensino Médio: orientações complementares aos Parâmetros Curriculares Nacionais - ciências da natureza, matemática e suas tecnologias. Brasília, DF: MEC/Semtec, 2002. Disponível em: http://portal.mec.gov.br/seb/arquivos/pdf/CienciasNatureza.pdf. Acesso em: 5 jan. 2021.

CHASSOT, Aticco. Alfabetização científica: uma possibilidade para a inclusão social. Revista Brasileira de Educação, v. 8, n. 22, p. 89-100, 2003.

DINIZ, Debora. Carta de uma orientadora: o primeiro projeto de pesquisa Brasília: Letras Livres, 2012.

FREIRE, Paulo. Pedagogia da autonomia: saberes necessários à prática educativa. 30 . ed. São Paulo: Paz e Terra, 2004.

IBGE. Pesquisa Nacional por Amostra de Domicílios Contínua. Instituto Brasileiro de Geografia e Estatística, 2019. Disponível em:

https://www.ibge.gov.br/estatisticas/multidominio/condicoes-de-vida-desigualdade-epobreza/17270-pnad-continua.html?edicao=24437\&t=resultados. Acesso em: 12 ago. 2021.

MELO, Hildete Pereira; RODRIGUES, Ligia. Pioneiras da ciência no Brasil: uma história contada doze anos depois. Ciência e Cultura, v. 70, n. 3, p. 41-47, jul./set. 2018.

Revista Extensão \& Cidadania, v. 9, n. 16, p. 166-177, jul./dez. 2021. 
OLIVEIRA, João Paulo de; COSTA, Conceição Leal. Desenvolvimento de projetos e(m) educação para a cidadania - o caso do Programa de Apoio à Extensão do IFRN. Revista Brasileira da Educação Profissional e Tecnológica, v. 1, n. 14, p.1-15, jan./jun. 2018.

OLIVEIRA, João Paulo de; COSTA, Conceição Leal. O papel da extensão na formação de estudantes do IFRN Campus Mossoró: reflexões em torno de educação para a cidadania a partir de um estudo de caso. In: SANTOS, S. C. A dos; CAVALCANTE, I. F.; LEMOS, E. C.; FERREIRA, M. C.; COSTA, M. L. Educação \& Sociedade: formação profissional, educação a distância e tecnologias. São Luís: IFMA, 2020. p. 225-262. Disponível em: https://memoria.ifrn.edu.br/bitstream/handle/1044/1810/4.Educacao-eSociedade.pdf?sequence=1\&isAllowed=y. Acesso em: 1 jan. 2021.

PAVIANI, Neires M. Soldatelli; FONTANTA, Niura M. Oficinas pedagógicas: relato de uma experiência. Conjectura, v. 14, n. 2, p. 77-88, maio/ago. 2009.

PIETROCOLA, Maurício. Construção e realidade: modelizando o mundo através da Física. In: PIETROCOLA, Maurício (Org.). Ensino de Física: conteúdo, metodologia e epistemologia numa concepção integradora. Florianópolis/Brasília: Editora da UFSC/INEP, v. 1, 2001. p. 9-32.

SANTOS, Milton. O espaço do cidadão. São Paulo: Editora da USP, 2012.

VIANNA, Deise Miranda. Formação cidadã para nossos alunos - um contexto cultural para o ensino de Física. In: MARTINS, André Ferrer P. (Org.). Física ainda é cultura? São Paulo: Livraria da Física, 2009. p. 131-149.

YANNOULAS, Silvia Cristina (Coord.). Trabalhadoras: análise da feminização das profissões e ocupações. Brasília: Editorial Abaré, 2013.

Recebido: 10.05.2021

Aceito: 04.08.2021

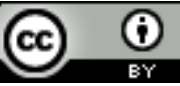

This work is licensed under a Creative Commons Attribution 4.0 International License.

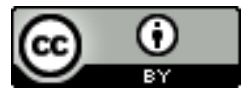

Este trabalho está licenciado com uma Licença Creative Commons - Atribuição 4.0

Internacional.

Revista Extensão \& Cidadania, v. 9, n. 16, p. 166-177, jul./dez. 2021. 